\title{
RESENHA: VOZES DA EDUCAÇÃO 20 ANOS: MEMÓRIAS, POLÍTICAS E FORMAÇÃO DOCENTE
}

\author{
Ana Valéria Dias Pereira ${ }^{\mathrm{i}}$
}

O livro Vozes da Educação 20 anos: memórias, políticas e formação docente é um importante instrumento para diferentes pesquisadores e pesquisadoras que buscam, no momento histórico contemporâneo brasileiro e latino-americano, formas de contribuir tanto com a resistência ao acirramento de medidas neoliberais, impostas a cada dia com maior brutalidade, como na construção da vontade coletiva de transformação do modelo de sociedade vigente e, com isso, a construção de condições objetivas para o acontecimento da transformação.

Inicialmente as autoras Maria Tereza Goudard Tavares e Inês Ferreira de Souza Bragança, num convite irrecusável à leitura do livro, mostram que, para além de celebrar os 20 anos de um grupo de pesquisa que nasceu da vontade de contribuir com a visibilidade de vozes que foram, e são, historicamente abafadas, reprimidas, invisibilizadas, o livro se propõe a compartilhar com os leitores e leitoras experiências coletivas de sujeitos vinculados ao Grupo Vozes ao longo da trajetória do grupo desde seu nascimento.

Importante destacar que, mesmo diante do cenário, no mínimo, perturbador do Brasil hodierno, as anfitriãs do livro, sem nenhuma proximidade com a Síndrome de Pollyana, revelam a força que os escritos nele contidos trazem quando, corroborando com Mia Couto, enfatizam o entendimento de que a conjuntura atual também se configura como um cenário propício à criação de novas formas de luta.

As autoras também salientam que a materialidade do quinto livro de um grupo fundado na diversidade se traduz numa manifestação concreta de que o desafio de se caminhar coletivamente em prol de um objetivo em comum, mesmo que este coletivo seja diverso em relação às suas concepções sobre a produção do conhecimento, é plenamente possível quando se interioriza como principio basilar da caminhada o sentido ético da responsabilidade.

Tanto no referido convite à leitura como no prefácio do livro, os leitores encontrarão concisos, fundamentados e ricos resumos da obra. Resumos cujos autores, apesar de abordarem conteúdos comuns, privilegiaram em suas narrativas distintos enfoques.

A importância do prefácio escrito por Ricardo Vieira (professor em Leiria), dentre outras coisas, reside na oportunidade que o leitor terá de conhecer particularidades de toda a obra. O autor do prefácio, além de reunir as ideias contidas em textos construídos teórica e metodologicamente de formas diferenciadas, desenha um sucinto histórico sobre a origem e trajetória do Grupo Vozes e exterioriza não somente sentimentos de alegria pela tarefa confiada a 
ele, mas, também, seus primeiros encontros com integrantes do Vozes e o desenvolvimento daquelas relações.

O leitor que desejar conhecer os conceitos de alteridade e exotopia, por meio do diálogo com as atividades práticas deste grupo de pesquisa e extensão Vozes da Educação, vai contar com a importante e essencial produção de Mairce da Silva Araújo, Assim passaram vinte anos: Memórias e Histórias do Grupo Vozes da Educação em São Gonçalo.

É o texto de Mairce Araújo que inaugura a primeira de duas partes do corpo do livro formada por três textos e intitulada Sobre dispositivos teórico-metodológicos: caminhos em construção. Nele a autora relata a história do grupo Vozes e sua relação com o Grupalfa (vinculado à Faculdade de Educação da Universidade Federal Fluminense) e que possui o mesmo compromisso com a classe popular. Também é aqui que o leitor encontra detalhes sobre as atividades que aconteceram e acontecem, em escolas públicas de São Gonçalo, desenvolvidas pela equipe do Vozes sob a lógica dialógica presente em obras de autores como Bakhtin.

Quem também tiver interesse em conhecer uma importante parte da história da educação gonçalense, não pode abster-se de ler este texto. Nele o leitor vai encontrar relatos preciosos sobre, por exemplo, a Escola Municipal Raul Veiga, primeira escola da rede pública municipal de São Gonçalo e sobre o Instituto de Educação Clélia Nanci que, pertencente à rede pública estadual, possui um papel fundamental na formação inicial de parte significativa do quadro de professoras que atuam nas séries iniciais das escolas do município. Tudo isso por meio de análises sobre a relação entre sociedade e educação em âmbito local e nacional, historicamente fundamentadas.

O segundo texto do livro, Vozes na Diferença: passagem por um grupo de pesquisas, de autoria da professora Anelice Ribetto, é indicado para o aprofundamento de conceitos que envolvem as análises de Derrida e Deleuze sobre as teias das relações.

Ribetto, neste texto, construiu um diálogo entre as abordagens desses autores, sobre o conceito de sociabilidade e o cotidiano no Vozes como um lugar de produção da amizade, por meio do exercício da alteridade que a convivência entre diferentes impõe aos componentes do grupo.

O referido texto prioriza um diálogo entre a história dos Seminários do Grupo Vozes com ideias desenvolvidas por Foucault e Deleuze em relação a dispositivos criados para contribuir com o protagonismo daqueles e daquelas que, historicamente, acostumaram a se calar. Ou seja, os Seminários são compreendidos como "máquinas de fazer ver e de fazer falar" (p. 31).

A autora também destaca que o entrecruzamento do levantamento da história cronológica dos Seminários e sua inserção e trajetória no Grupo Vozes, também resultam em reflexões sobre 
o desenvolvimento de questões relacionadas à Educação Inclusiva nas escolas municipais gonçalenses.

Jacqueline de Fatima dos Santos Morais, autora do terceiro texto do livro - Expedição Pedagógica: Estratégia de Formação Docente em Contexto Latino Americano -, desfrutando da beleza poética de Gabriel Garcia Marques, inicia suas reflexões sobre a importância de rememorar o vivido com o Grupo Vozes.

Lançando-se a Benjamin, Larrosa e outros, a autora analisa detalhes sobre a Expedição Pedagógica em Nequén - que se torna a parte central do seu texto - além de realizar importantes reflexões envolvendo a Pedagogia da Autonomia de Freire que, aos poucos, estruturam-se na ideia de que "todo projeto de pesquisa é também um projeto político!" (p. 46).

Assim, o leitor interessado em conhecer a engrenagem de ações contra hegemônicas, desenhada sob o ponto de vista do diálogo realizado entre a teoria e as experiências vividas em dois momentos e espaços distintos - uma experiência internacional (a Expedição) e uma experiência local (o Vozes) - , não deve deixar de ler esta parte do livro.

Em Itinerários e discussões epistemológicas, título dado para nomear o segundo bloco de textos do livro, é onde encontramos sete dos dez textos que formam o que chamamos de corpo principal do livro.

Este bloco de textos é inaugurado por Maria Tereza Goudard Tavares, uma das três professoras fundadoras do grupo que comemora 20 anos de uma valiosa história de produção do conhecimento orientada pela ideia de se construir e consolidar uma escola democrática para a classe popular.

O texto de Maria Tereza, intitulado (Re) pensando o Vozes da Educação em São Gonçalo: Desafios contemporâneos da formação de professores em periferias urbanas, é um texto imperdível para o leitor politicamente ativo que deseja conhecer os caminhos percorridos por um grupo que pensou, realizou e realiza ações que objetivam a formação da vontade coletiva em professoras e professores no que tange a construção de uma escola verdadeiramente democrática.

Para os que pesquisam e se interessam por temáticas que envolvem a formação de professores, neste texto, também, dispomos de um levantamento das entidades científicas nacionais que têm debatido a temática durante as últimas décadas (inclusive a referência de um Estado da Arte sobre o assunto). Além de podermos contar com uma reflexão crítica sobre o envolvimento do Banco Mundial (BM) e do Fundo Monetário Internacional (FMI) nas políticas de formação docente.

Revista Interinstitucional Artes de Educar. Rio de Janeiro, V. 2 N. Especial - pag 327-334 (jun - out 2016): "Vozes da Educação" 
Autores como Marilena Chauí, Walter Benjamin, Paulo Freire, Gramsci, e outros, dialogam, no texto de Maria Tereza, com as experiências de professoras da Educação Infantil. Diálogos que perpassam por caminhos que problematizam o conceito de formação de professores e que contribuem com o desenho da formação de docentes sob a perspectiva de ser este, também um direito da criança.

O segundo texto deste bloco do livro é o de Marcia Soares de Alvarenga: Polifonia e dialogismo como perspectivas epistemológicas na pesquisa e extensão do Vozes da Educação.

Neste texto temos a oportunidade de compreender historicamente o conceito de polifonia, sua apropriação pelo grupo Vozes e sua relação com a Educação popular, mais especificamente com a Educação de Jovens e Adultos.

Evocando, dentre outros, Gramsci, Bakhtin, Thompson, Paulo Freire e Haydèe Figueiredo, a autora problematiza o conceito de polifonia e identifica a relação do grupo Vozes com este conceito sob perspectiva dialética e dialógica segundo a qual sujeito e objeto não se separam.

Neste caso, nas palavras da autora, sob a perspectiva bakhitiniana, o Vozes se configura como uma grande tenda que entende o direito à palavra como um direito humano. Direito que se justifica por ser a linguagem "produzida histórica e socialmente pelos homens onde estes e os sentidos se constituem dialeticamente" (p.87). Dito de outra forma, uma grande tenda onde diferentes vozes acampam, conversam, constroem e reconstroem formas de resistência e de mudança social.

Os leitores que pesquisam a educação popular encontrarão neste texto um valioso e fecundo diálogo entre teorias revolucionárias e práticas encontradas em salas de aula, por meio de pesquisas de campo realizadas em escolas de periferia urbana (as quais recebem destaque da autora). Além do posicionamento político/pedagógico, cuidadosamente fundamentado teoricamente, sobre ser a Educação de Jovens e Adultos um lugar de conquista e direito à educação.

Seguindo na mesma esteira da ideia da tenda como lugar de garantia do direito à palavra, o livro nos proporciona o contato com o texto de Regina de Fátima de Jesus, cujo título já nos orienta sobre o que vamos encontrar pela frente: $O$ Vozes da Educação e as vozes negras gonçalenses, memórias entrelaçadas.

Contando uma parte de sua trajetória acadêmica e profissional, inclusive sobre como aconteceu sua inserção na Faculdade de Formação de Professores da UERJ e no grupo Vozes, a autora, além de nos trazer sua visão sobre o grupo, a traz sob perspectiva quanto à importância de se "voltar ao passado para ressignificar o presente". Uma curiosidade é o destaque, de beleza 


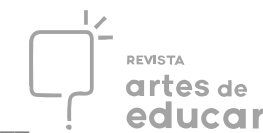

poética e consistência histórica, que a autora realiza sobre o ideograma africano Sankofa que se traduz na ideia de que "nunca é tarde para voltar e apanhar aquilo que ficou para trás".

Esta parte do livro é de relevante importância para professores e professoras que buscam se apropriar de detalhes quanto a construção e implementação da Lei 10.639 de 2003. Neste texto, a autora, num diálogo com Milton Santos e Petronilha Silva, evidencia a importância da formação de professores como reeducação em relação a questões étnico-raciais, por meio de ações antirracistas e desmonte de visões eurocêntricas.

O leitor que busca compreender a importância da oralidade para recuperação da história e consequente ressignificação do presente, não pode deixar de ler este texto que tem como um de seus objetivos desmascarar a ideia da democracia racial no Brasil que foi construída durante a escrita de uma história com propósitos de atender aos interesses de uma elite dominante, europeia e colonizadora, e que permanece no imaginário de parte significativa da população brasileira.

Lúcia Velloso Maurício, a autora do quarto texto do segundo bloco do corpo especial do livro, contribui com o conjunto deste preciso instrumento de pesquisa com o texto Memórias entre Vozes.

De forma acurada a trajetória acadêmica e profissional da autora, misturando-se com fragmentos relevantes da história da educação em tempo integral brasileira (com destaque para os CIEPs), é contada nas linhas desta parte do livro. Linhas que se configuram, inclusive, como um notável suporte teórico-metodológico para os pesquisadores da área.

É aqui também que os pesquisadores da Educação em Tempo Integral encontrarão um importante relato reflexivo sobre a história do Complexo Educacional de São Gonçalo em franco diálogo com Darcy Ribeiro e Aníso Teixeira, além de conclusões que conseguiu obter de sua análise sobre as representações que foram formadas em relação à escola de turno integral a partir de um jornal de circulação nacional (o Globo).

Quanto ao seu lugar no grupo Vozes, a autora empreende uma detalhada radiografia do grupo, inclusive, por meio de uma análise comparativa entre o grupo de professores que integram o Mestrado em Educação da Unidade e o grupo de professores que integram o Vozes, entrelaçando-as com seus encontros, expectativas e atuações.

A cor da perfeição: educação popular e novos sentidos da devoção franciscana aos santos negros no Brasil colonial (1700-1750), texto de Luiz Fernando Conde-Sangenis, não obstante seguir caminhos distintos da pesquisa abordada no texto de Regina de Jesus se traduz num importante instrumento para pesquisas que seguem a linha de pensamento que culminou na Lei da 10.639/2003. Esta afirmativa é calcada na observância de que, neste texto, encontramos 
partes tanto da história da cultura negra brasileira, como da participação do negro na formação da sociedade nacional contada fora dos padrões eurocêntricos.

Neste texto, que inicia-se com uma saudação a uma das fundadoras do grupo Vozes, Haydèe Ribeiro, o autor nos conta particularidades da ordem franciscana que se traduzem em movimentos emancipatórios, primordiais para entendermos os mecanismos de lutas utilizados pelos povos negros no Brasil Colônia, assim como os resultados obtidos já naquela época. '

Para os pesquisadores que se envolvem com a investigação sobre a importância das irmandades, formadas por negros, para os movimentos contra o sistema escravocrata, este texto é de extrema relevância historiográfica (inclusive por trazer dados de documentos oficiais como o Alvará Régio de 1720, e outros), filosófica e política. Pois o autor, além de descrever fatos, analisa os dados evocando Euclides da Cunha, Manoel Bonfim, Gilberto Freyre, Darcy Ribeiro, dentre outros, de maneira que o leitor tenha em mãos um valioso suporte para o prosseguimento de pesquisas do gênero.

Inês Ferreira Souza de Bragança, com Concepções e práticas de pesquisa narrativa: diálogos entre os núcleos Vozes, Gruprodoci e Gepec, é a autora do nono texto do corpo principal do livro.

Os leitores que desejarem compreender o conceito de redes de histórias em Benjamin encontrarão, neste texto, uma abordagem didática que muito contribui com pesquisas desta ordem.

Para quem deseja entender as microinterações sócio-políticas do cotidiano, deve ler esta pertinente contribuição de Inês Bragança que, por meio da narrativa de sua própria trajetória acadêmica e profissional e por meio dos relatos de integrantes dos grupos que formam o título deste texto, dialogou com conceitos formulados por Marinas e Ricouer que versam sobre as narrativas mediante a construção de cenas.

Com base em Larrosa e Nóvoa, a autora produz uma análise sobre as narrativas dos coordenadores dos grupos em questão, através da qual nos sinaliza questões como a importância da pesquisa (auto) bibliográfica, da formação do professor reflexivo e pesquisador e da relação entre consciência e linguagem, importantíssima para o leitor que deseja desenvolver pesquisa do gênero.

No décimo texto do corpo principal do livro, e sétimo do segundo bloco, a autora Elaine Ferreira Rezende de Oliveira desenvolve uma análise sobre $A$ produção discente acerca das políticas educacionais do núcleo de pesquisa e extensão vozes da educação (1999-2015): Por uma economia política do cotidiano. 


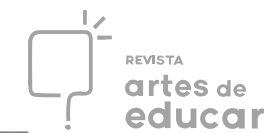

Nesta análise Elaine Ferreira produz um minucioso levantamento da produção dos discentes orientados por professores ligados ao grupo Vozes e, dentre outras questões importantes, a autora descreve um panorama precioso para compreensão do compromisso do grupo com a educação popular tanto do município de São Gonçalo/RJ, lugar onde se encontra a sede física do grupo, como da educação popular como um todo.

Do ponto de vista metodológico, uma característica que difere este texto dos demais é a sua natureza quanti-qualitativa, que se constitui numa contribuição importante para quem busca realizar pesquisas com este formato.

Além desta parte metodológica, uma grande contribuição deste texto é a reflexão que a autora realiza entre fenômenos globais e locais. E, aí, quem estiver interessado numa leitura que contribui com a compreensão histórica sobre a articulação entre fenômenos globais (como as políticas neoliberais a partir dos anos de 1990) e fenômenos locais, por meio de referenciais teóricos como Michael Apple, Pierre Boudieu, Luiz Carlos de Freitas, dentre outros, não deve deixar este texto sem ter sido lido.

A importância do livro como extensão e propagação da essência do Vozes de visibilizar os movimentos contra-hegemônicos que, nas palavras de Apple, acontecem a todo momento e em todos os lugares do planeta, está registrada, de forma magistral, nas palavras das professoras da Red de Docentes que Hacen Investigación Educativa, Andrea Arcuri, Noemí Cavallini, Natalia Lagos, Graciela Martínez, Karina Pérez, Fermina Rivas e Teresa Romero, que escrevem o posfácio do livro.

As referidas professoras fazem uma breve descrição tanto da conjuntura configurada pelos fortes ataques neoliberais que os Estados nacionais latino-americanos têm sofrido, como da necessária união das forças contra-hegemônicas que existem em cada um destes países.

E, por último, mas não menos importante, um destaque a ser realizado é a importância deste livro para a luta de classes. Dito de outra forma, o livro cumpre com o compromisso do Grupo Vozes da Educação em buscar criar condições objetivas de visibilidade das vozes que contam suas experiências, resistências e lutas contra a organização das sociedades que insistem em separar os seres humanos entre, pelo menos, dois grandes grupos: os que governam e os que são governados. Ou seja, o maior destaque de todos os textos que constituem este livro é a importância que cada um confere a história contada, nas palavras de Benjamin, a contrapelo.

Enfim, uma leitura imperdível! 
${ }^{\text {i }}$ Doutoranda em Educação pela Universidade Federal do Estado do Rio de Janeiro (UNIRIO), Mestre em Educação pela Faculdade de Formação de Professores da Universidade do Estado do Rio de Janeiro (UERJ), Membro do GEPAC/UNIRO (Grupo de Estudos e Pesquisa: Avaliação e Currículo) e do NUFIPE/UFF (Núcleo de Estudos e Pesquisas em Filosofia, Política e Educação) e Professora Supervisora Educacional da Rede Pública Municipal de São Gonçalo/RJ. 